\title{
天水-秦安地区新生代构造和地貌演化的 碎屑锆石证据
}

\author{
王治祥 (1)2), 梁美艳 ${ }^{(3)}$, 孙宇奇 ${ }^{(1) 2)}$, 戴高文 ${ }^{\text {(1)(2) }}$
}

(1) 中国地质大学地球科学学院, 生物地质与环境地质国家重点实验室, 武汉 430074;

(2) 中国地质大学地球科学学院, 流域关键带演化实验室, 武汉 430074;

(3) 中国地质大学公共管理学院区域规划系, 武汉 430074;

(4) 中国地质大学公共管理学院, 地理环境与国家公园实验室, 武汉 430074

*通讯作者, E-mail: liangfan99@126.com

收稿日期: 2016-07-13; 接受日期: 2016-11-09; 网络版发表日期: 2016-11-23

国家自然科学基金项目(批准号: 41572339, 41002051, 41322013)和中央高校基本科研业务费专项资金项目(批准号: CUG160217)资助

摘要 天水-秦安地区保存有多种成因类型的新生代沉积物, 其物质来源及其变化对于研究青藏高原东北部 的隆升剥蚀历史、构造变形方式以及与之相关的地貌演化过程具有重要意义. 本文通过碎屑锆石 $\mathrm{U}-\mathrm{Pb}$ 年龄物 源示踪方法, 对该区的古近纪洪积砾岩、新近纪河流和湖相沉积进行了分析, 并与中新世以来的风尘堆积进行 了对比. 结果显示: 1) 古近纪洪积砾岩中包含大量亲扬子地块的 560 1100Ma的锆石颗粒, 但这一年龄的锆石颗 粒在早中新世河流相沉积中显著减少, 同时出现了大量200 360Ma的锆石颗粒, 指示着古近纪洪积砾岩主要来 自西秦岭的中部和/或南部, 而早中新世河流相沉积主要来自西秦岭北部;2) 约11.5Ma以来, 该区河流相沉积以 380 450Ma的锆石颗粒占主导, 与六盘山南部岩体的年龄一致, 指示着六盘山南部的初始隆升; 3) 该区晚中新 世湖相沉积的锆石年龄分布明显不同于同时期的河流沉积物, 但与秦安中新世风成红土、晚中新世一上新世三 趾马红土及第四纪黄土十分相似, 指示着该区中新世的细颗粒水成沉积物很可能主要为风尘物质. 本文的研 究揭示出天水-秦安地区新生代沉积物的物源转变和地貌演化均与青藏高原东北部的阶段性隆升密切相关, 特 别是晚渐新世-早中新世青藏高原北部的隆升, 可能既为中新世风成红土的出现创造了物源和风动力条件, 也 为其堆积创造了地貌条件.

关键词碎屑锆石, 物源, 构造隆升, 地貌演化, 天水-秦安地区

\section{1 引言}

新生代以来, 东亚地区的环境和地貌格局发生了 深刻的变化. 大量古地理学的研究表明, 古近纪/新近
纪之交东亚环境格局由行星风系气候格局转变为新 近纪以来的季风气候格局(Sun和Wang, 2005; Guo等, 2008). 这一转变导致了亚洲内陆地区出现内陆型荒 漠, 而中国中东部地区受季风气候影响而变得湿润. 对

$\begin{array}{ll}\text { 中文引用格式: } & \text { 王治祥,梁美艳, 孙宇奇, 戴高文. 2016. 天水-秦安地区新生代构造和地貌演化的碎屑锆石证据. 中国科学: 地球科学, 46: 1633-1644, doi: } \\ & 10.1360 / N 072016-00247\end{array}$ 英文引用格式: $\begin{aligned} & \text { Wang Z X, Liang M Y, Sun Y Q, Dai G W. 2016. Cenozoic tectonic and geomorphic evolution of the Longxi region in northeastern Tibetan Plateau } \\ & \text { interpreted from detrital zircon. Science China Earth Sciences, doi: 10.1007/s11430-016-5247-9 }\end{aligned}$ 
于东亚季风-内陆干旱系统的形成, 古气候模拟的研究 将其归因于青藏高原的隆升(Ramstein等, 1997; An等, 2001; Liu和Dong, 2013; Liu等, 2015b). 近年来, 对于高 原的隆升历史和现代东亚季风的起源均获得了大量进 展(Guo等, 2002, 2008; 肖国桥等, 2014; Wang等, 2014; Li等, 2015), 进一步强化了高原隆升与东亚季风-内陆 干旱系统形成之间的联系. 但是, 已有的高原隆升和 东亚季风系统起源的地质证据分别独立分布于高原 区和东亚季风区(肖国桥等, 2014), 缺乏同时包含高原 隆升和东亚季风起源信息的地质载体.

近年来, 在陇西秦安地区发现了底界年龄约为 25Ma的近乎连续的风尘堆积(Guo等, 2002; 强小科等, 2010), 揭示出亚洲内陆型荒漠和现代东亚季风系统形 成于晚渐新世-早中新世时期(Guo等, 2002, 2008). 由 于陇西地区既处于东亚季风区和内陆干旱区的过渡 地带, 也处于青藏高原东北边缘, 因而能够同时敏感 地记录青藏高原的隆升和东亚季风的演化. 陇西地区 保存有包括中新世风成红土在内的多种新生代沉积 物, 其为进一步探讨高原隆升与东亚季风系统起源之 间的联系提供了理想的研究素材. 前人已对这些沉积 物的成因和地层年代进行了深入研究, 本文在前人研 究的基础上, 对该区不同类型的新生代沉积物开展了 碎屑锆石物源分析, 以期探讨如下两方面问题: (1) 陇 西地区新生代沉积物物源经历了怎样的变化? 这些变 化反映了该区怎样的构造和地貌演化历史? 与青藏 高原东北部的阶段性隆升有何联系? (2) 该区广泛发 育有指示现代东亚季风气候的中新世风尘红土(Guo 等, 2002, 2008, 2010; Hao和Guo, 2004, 2007; 袁宝印等, 2007; 詹涛等, 2010; Ge等, 2012), 这些风尘堆积的出现 及空间分布与区域构造和地貌演化有何联系?

\section{2 区域地质概况}

天水-秦安地区位于青藏高原东北边缘, 与祁连 山、西秦岭、六盘山等山系相邻(图1). 根据研究区 的地貌和沉积物分布特征, 可将研究区划分为三个构 造-地貌单元(Meng和Zhang, 2000; Guo等, 2010): (1) 位于西秦岭北缘断裂带以南的西秦岭山区, 主体海拔 1900 2100m, 地貌以山地及山间盆地为主, 其中包括 西和-礼县盆地、徽县-成县盆地等; (2) 沿NWW方向 分布于西秦岭北缘的坳陷带, 该坳陷带受西秦岭北缘
断裂带的控制, 该区宽约 $30 \mathrm{~km}$, 海拔相对较低, 主体海 拔1500 1700m, 新近纪水成沉积及受流水改造的风尘 堆积主要沿该坳陷带分布(图1); (3) 坳陷带以北的基 岩台地, 主体海拔 1800 1900m, 其是中新世典型风尘 堆积的主要分布区.

坳陷带以北的基岩台地属祁连山褶皱带, 是早志 留秦祁昆古海板块俯冲增生而形成的 $(X u$ 等, 2010), 而 以南为西秦岭褶皱带, 即现今的西秦岭山地, 是由华南 板块不断向北俯冲增生至晚三叠时秦岭洋闭合而形 成的(Meng和Zhang, 2000). 西秦岭北缘断裂带位于西 秦岭山地的北麓(图1), 其东端始于渭河盆地以西, 西 端可能到达贵德盆地附近, 是青藏高原东北部一条重 要的NWW断裂带, 它由一组近于平行的断裂组成(王 志才等, 2006). 低温热年代结果显示西秦岭北缘断裂 在新生代时期遭受了多期的快速逆冲(Wang等, 2011), 初始活动大约发生在 $50 \mathrm{Ma}$, 可能响应了印度-欧亚板 块的初始碰撞(Clark等, 2010; Wang等, 2011). 在陇西 地区, 沿着西秦岭北缘断裂带两侧, 发育了一系列盆 地, 如武山盆地、天水盆地等. 这些盆地广泛发育了 新生代沉积物, 其与下伏前新生代岩层呈角度不整合 接触(Wang 等, 2011, 2012).

基于岩性特征和生物化石记录, 区域地质调查部 门把陇西地区的新生代地层分为古近系“固原群”和 新近系“甘肃群”(地质部陕西省地质局区域地质测量 队, 1968; 地质部甘肃省地质局第三区域地质测量队, 1974; 䍜毓沛和蔡体梁, 1984), 两者呈角度不整合接触 (李吉均等, 2007; 袁宝印等, 2007; Wang等, 2011). 固 原群主要由一套砾岩组成, 这套砾岩层的分布向西至 少可至渭源县, 向东至六盘山西麓, 出露厚度从几十 米至几百米, 在甘泉一带厚度可达 $600 \mathrm{~m}$ 以上, 向北逐 渐减薄(地质部陕西省地质局区域地质测量队, 1968; 地质部甘肃省地质局第三区域地质测量队, 1974).

新近系的甘肃群包含有多种成因类型的沉积物, 包括典型风成红土-古土壤序列、受流水作用改造的风 成红土、河流相沉积、湖相沉积等(袁宝印等, 2007; Guo等, 2010; 梁美艳等, 2013). 其中, 水成沉积主要 发育在西秦岭北缘坳陷带及西秦岭的山间盆地内(图 1), 主要由河流相砂岩、湖相泥灰岩、洪泛平原泥岩 等组成, 出露厚度在武山盆地可达 $2200 \mathrm{~m}$ 左右(Liu等, 2015a), 但在天水盆地的窑店剖面仅为 $240 \mathrm{~m}$ 左右(李吉 均等, 2007). 古地磁定年揭示出甘肃群的底界年龄在 


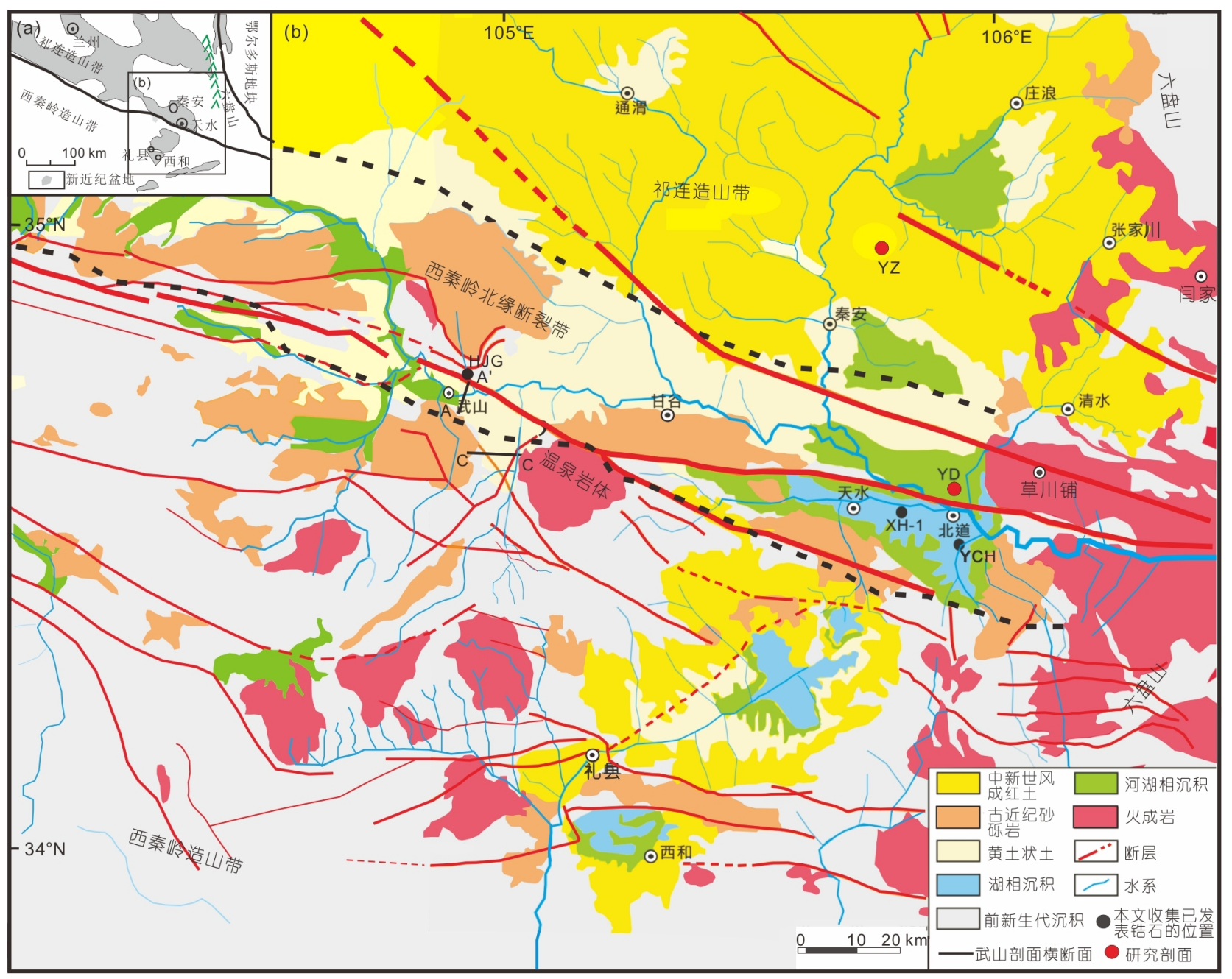

图 1 研究区的大地构造背景图(a)及区域地质图(b)

(b) 黑色虚线划分了该区3个构造单元, 即西秦岭造山带、西秦岭北缘断裂带及北部的祁连造山带(根据梁美艳等(2013)和Liu等(2015a)修改)

武山盆地约为 $22 \mathrm{Ma}(\mathrm{Liu}$ 等, 2015a), 在天水盆地的窑店 剖面为12.4Ma左右(李吉均等, 2007). 典型风尘红土古土壤序列主要发育在坳陷带以北的基岩台地及盆地 边缘的高地之上(图1), 其分布范围向北至少可达到华 家岭顶部(海拔约 $2400 \mathrm{~m}$ ), 向东至六盘山西麓(Guo等, 2010), 其底界年龄可追溯至 25Ma左右(Guo等, 2002; 强小科等, 2010).

\section{3 材料与方法}

本研究所涉及的水成剖面(窑店剖面, $105^{\circ} 55^{\prime} \mathrm{E}$, $34^{\circ} 38^{\prime} \mathrm{N}$ ) 位于天水市东北渭河以北、牛头河以西的窑 店村边, 处于西秦岭北缘坳陷带内(图1). 整个剖面由 古近纪洪积砾岩与新近纪水成沉积组成, 二者呈角度
不整合接触, 剖面顶部被第四纪黄土不整合覆盖. 其 中, 古近纪洪积砾岩层厚约 $90 \mathrm{~m}$, 其与下伏泥盆系地 层呈角度不整合接触. 这些砾岩呈浅砖红色, 由厚层 状角砾岩夹砂质条带组成, 其砾石成分复杂, 磨圆度 较差, 大小混杂, 分选较差(李吉均等, 2007). 新近纪 地层厚约 $240 \mathrm{~m}$, 主要由浅湖、河道与洪泛平原沉积构 成(李吉均等, 2007). 剖面顶部被第四纪黄土不整合 覆盖. 古地磁年代研究揭示出该剖面的新近纪地层 跨越12.4 6.5Ma(李吉均等, 2007). 本次研究所涉及的 碎屑锆石样品采自窑店剖面的 6 个层位, 其中 4 个样品 (YD-2, YD-5, YD-7, YD-10)的数据为本文报道, 其余2 个样品(YD-9和YDE)来自前人已发表的数据(梁美艳 等, 2013; Liu等, 2015a). 样品YD-2采自该剖面上部的 
灰绿色细颗粒湖相沉积层, 其古地磁年代约为 7.6Ma; YD-5采自剖面中部的洪泛平原古土壤层, 其中包含较 多细砂颗粒, 其古地磁年代约为 9.4Ma; YD-7采自该 剖面下部的河流相砂岩层, 与前人发表的样品 YD(Liu 等, 2015a)处于同一层位, 其古地磁年代约为 $10.5 \mathrm{Ma}$; YD-9的数据来自于梁美艳等(2013), 为河流相砂岩, 其 年代约 11.5Ma; YDE和YD-10采自剖面底部的古近纪 砾石层, YDE处于砾石层顶部, 其年代约为 $30 \mathrm{Ma}(\mathrm{Liu}$ 等, 2015a), YD-10处于YDE下部约30m处, 因此其年代 $>30 \mathrm{Ma}$, 但确切年代未知.

本研究所涉及的风成剖面(杨赵剖面, $35^{\circ} 01^{\prime} \mathrm{N}$, $105^{\circ} 48^{\prime} \mathrm{E}$ )位于天水市秦安县莲花镇杨赵村, 处于研究 区北部的基岩台地之上(图1). 该剖面与下伏的早志留 纪变质岩呈角度不整合接触, 顶部被第四纪黄土不整 合覆盖, 剖面厚 $231.9 \mathrm{~m}$. 剖面上部 $180.2 \mathrm{~m}$ 为典型的黄 土-古土壤序列, 下部地层受片流作用影响, 局部存在 水流作用的层理, 在 $221.1 \mathrm{~m}$ 之下的地层中可见到少量 基岩碎屑(Hao 和Guo, 2007). 详细的古地磁定年揭示 出该剖面的年代为21.4 11.4Ma(Hao和Guo, 2007). 我 们之前的研究(梁美艳等, 2013)报道了采自该剖面下 部 $18 \mathrm{Ma}$ 的样品YZ-2的部分数据. 本次研究报道采自 该剖面中部约 15.3Ma的样品YZ-3(图2), 并对YZ-2进 行了更多锆石颗粒的测试.

为对比研究区内不同地点、不同类型沉积物的物 质来源, 收集了前人发表的武山剖面 5 个样品(WS25、

WS23、WS15、WS8和WS1)的碎屑锆石年龄数据(Liu 等, 2015a). 武山剖面与窑店剖面同处于西秦岭北缘 坳陷带内, 其年代跨越22 6Ma(Wang等, 2012; Liu等, 2015a), 沉积物主要以河流相、湖相沉积为主. 前人 发表的 5 个样品均采自冲洪积相砂砾层, 其古地磁年 龄依次为 $21.4 、 19.2 、 14.1 、 9.8$ 和6Ma. 很显然, 这些 砂砾岩样品的物源主要来自剖面周边山系岩石的风 化产物, 因此这些样品可代表武山盆地不同时期物源 供给区的碎屑锆石特征. 此外, 为确定窑店剖面和武 山剖面沉积物与周边山系的物源关系, 并探讨这些山 系的隆升剥蚀历史, 收集了西秦岭和六盘山主要岩体 的年龄以及河流沉积物的碎屑锆石年龄数据(Zhang 等, 2006; Cao等, 2011; 梁美艳等, 2013; Liu等, 2015a). 前人所发表的这些冲积物样品的锆石粒径绝大多数 $>100 \mu \mathrm{m}$ (梁美艳等, 2013; Liu等, 2015a), 排除了粉尘 物质的影响, 因此可利用这些沉积物的碎屑锆石特征
代表周边物源的总体特征.

锆石的分离按照传统方法进行: 每个样品取 $1 \mathrm{~kg}$ 左 右进行淘洗, 然后利用重液及磁力分离技术将锆石分选 出来, 之后在双目显微镜下进一步挑选. 将挑选的锆石 在显微镜下随机选取约 300 颗粘在双面胶上, 灌上环氧 树脂制成靶, 并打磨抛光. 在进行激光剥蚀测年之前利 用阴极发光扫描电子显微镜对所有锆石进行CL照相, 以便在测试时避开锆石内部的包裹体和裂隙. 每个样品 随机分析了 60 140颗锆石. 其中, 样品YZ-2、YD-2(其 中60颗锆石)、YD-5和YD-7的锆石U-Pb定年在中国地 质大学地质过程与矿产资源国家重点实验室的激光 剥蚀等离子质谱系统(LA-ICP-MS)上完成, 分析方法 详见文献(Liu等, 2010). 样品YD-5和YD-7的测试采用 $32 \mu \mathrm{m}$ 直径的激光束, YZ- 2 和YD- 2 的测试采用 $24 \mu \mathrm{m}$ 直 径的激光束, 每测 8 个样品测 2 次标样, 分析时采用的外 标都为哈佛大学标准锆石91500. 样品YZ-3、YD-2(其 中 80 颗锆石) 和YD-10的测试在天津地质调查中心的 激光剥蚀多接收等离子质谱仪(LA-MC-ICP-MS)上完 成, 测试采用的激光束直径为 $35 \mu \mathrm{m}$, 采用的外标为标 准锆石GJ-1, 每测 8 个样品测 2 次标样. 锆石的同位素年 龄计算采用ICPMSDataCal 8.0 (Liu等, 2010)软件分析, 普通 $\mathrm{Pb}$ 的校正采用Andersen (2002) 方法, 碎屑锆石年 龄谱的绘制采用软件DensityPlotter (Vermeesch, 2012) 完成. 本文所采用的所有锆石年龄数据的谐和度均达 到 $90 \%$ 以上, 对于 ${ }^{207} \mathrm{~Pb} /{ }^{206} \mathrm{~Pb}$ 年龄 $<1000 \mathrm{Ma}$ 的锆石颗粒, 采用 ${ }^{206} \mathrm{~Pb} /{ }^{238} \mathrm{U}$ 年龄; 对于 ${ }^{207} \mathrm{~Pb} /{ }^{206} \mathrm{~Pb}$ 年龄 $>1000 \mathrm{Ma}$ 的锆 石颗粒, 采用 ${ }^{207} \mathrm{~Pb} /{ }^{206} \mathrm{~Pb}$ 年龄.

\section{4 结果}

剔除谐和度 $<90 \%$ 的数据点后, 各样品的锆石 $\mathrm{U}-\mathrm{Pb}$ 年龄谱如图3所示. 其中, 窑店剖面底部的古近纪砾岩 样品YD-10共获取了 78 个有效数据点, 其锆石年龄分布 于约200 2700Ma区间(图3-a6), 其中大部分锆石(69\%) 的年龄落在 560 1100Ma区间内, 形成最显著的谱峰, 而其所包含的200 560Ma年龄段的锆石只占 $12 \%$, 明 显较前人发表的(Liu等, 2015a)古近纪砾岩顶部样品 YDE(48\%)少(图3-a5). 该剖面10.5Ma的河流相砂层样 品YD-7的锆石年龄谱分布特征与我们之前发表的河 流相样品YD-9 (11.5Ma)极其相似(图3-a3 和a4), 均有 $98 \%$ 的锆石颗粒分布于 $380 \sim 480 \mathrm{Ma}$ 区间, 表现为单一 


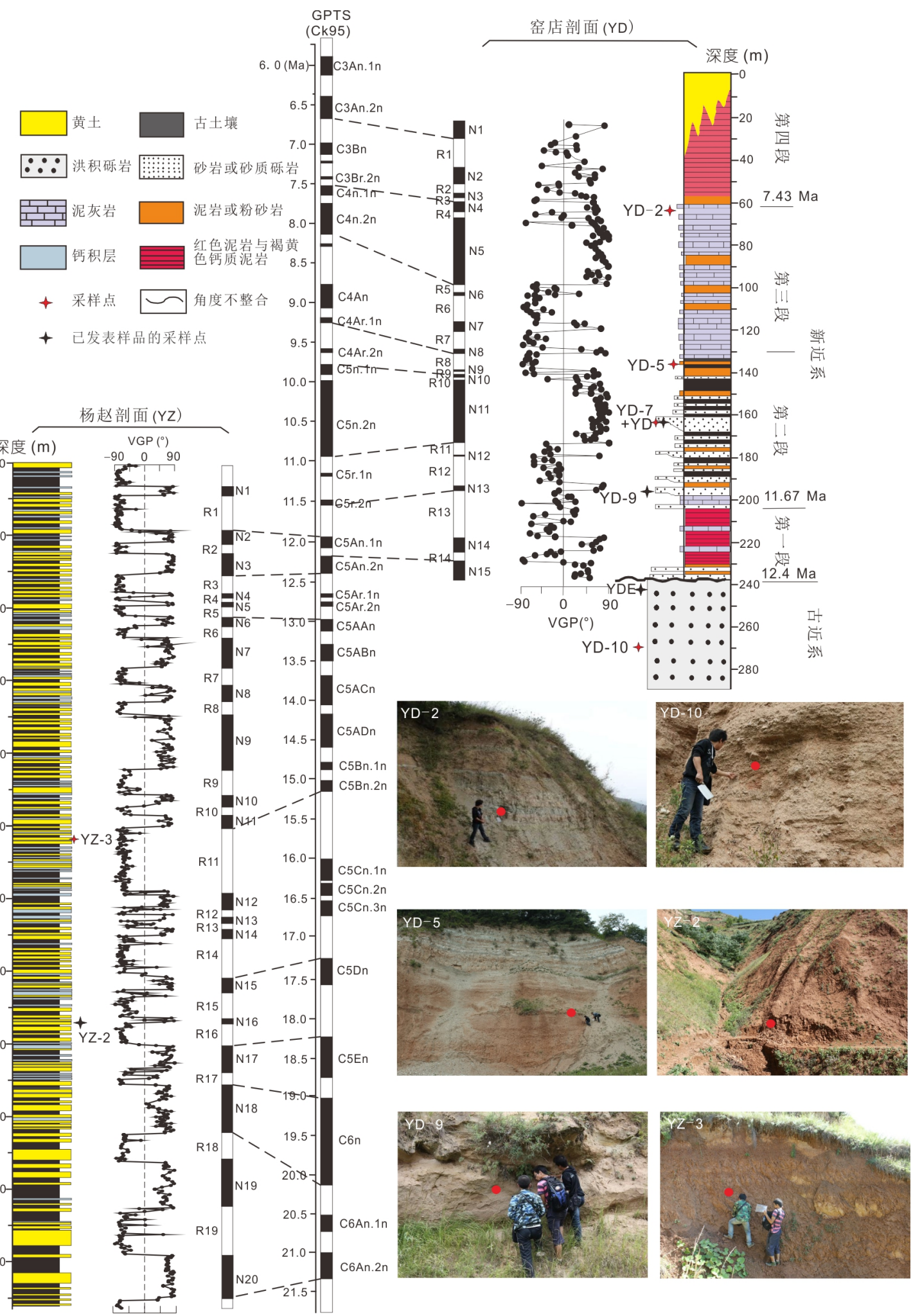

图 2 碎屑锆石样品的采样层位

窑店剖面的岩性地层和磁性地层引自李吉均等(2007), 杨赵剖面的岩性地层和磁性地层引自Hao和Guo(2007). 照片中红点指示采样部位 


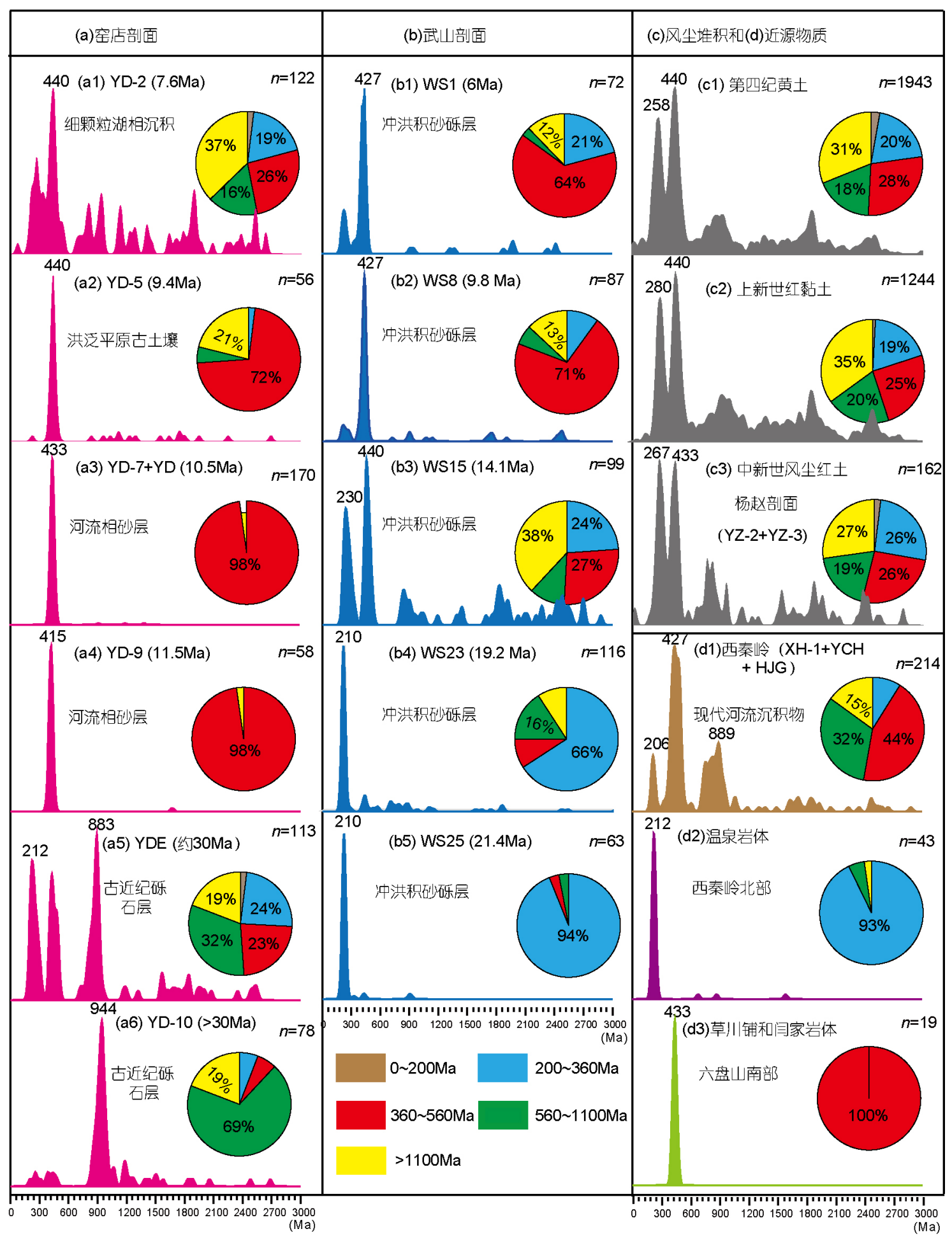

图 3 窑店剖面(a)、武山剖面(b)、风尘堆积(c)及近源物质(d)的碎屑锆石年龄分布

YD-9、YZ-2、XH-1及YCH引自梁美艳等(2013); YD、YDE、WS1、WS8、WS15、WS23、WS25及HJG引自Liu等(2015a); 上新世红黏土数 据引自Nie等(2014)和Shang等(2016); 黄土高原第四纪黄土数据引自Stevens等(2010)、Pullen等(2011)、Xiao等(2012b)、Che和Li(2013); 西秦 岭温泉花岗岩体锆石数据引自 Cao等(2011); 草川铺和阍家火成岩体锆石数据引自Zhang等(2006). 饼状图代表不同年龄碎屑锆石所占的比例 
的谱峰特征. 值得注意的是, 年龄处于 360 560Ma之 间的锆石在洪泛平原古土壤样品YD-5(9.4Ma)中也十 分显著, 所占比例达 $72 \%$, 表明其主要物源区可能与 YD-7和YD-9相同, 但同时混入了少量其他物源区的物 质. 剖面顶部的湖相沉积样品YD-2(7.6Ma)共获取了 122 个有效数据点, 其年龄分布范围在160 3000Ma之 间(图3-a1), 其主要谱峰分布在200 360和360 560Ma 之间, 同时 560 1100和 $>1100 \mathrm{Ma}$ 的锆石颗粒所占的比 例分别是 $16 \%$ 和 $37 \%$.

图3-c3中, YZ-2(18Ma)和YZ-3(15.3Ma)共获得 162 个有效数据点, 其在200 360、360 560、560 1100及 $>1100 \mathrm{Ma}$ 区间内锆石所占的比例大体上相似. 值得注 意的是, 中新世风尘红土的碎屑锆石 U-Pb年龄谱与上 新世红黏土(图3-c2)、第四纪黄土(图3-c1)较为相似, 指示着它们的物源区大致相似.

\section{5 讨论}

\section{1 新生代西秦岭和六盘山的隆升}

为探讨天水地区新生代沉积物的物质来源及其 变化所反映的区域构造演化, 我们对位于西秦岭北缘 坳陷带内的窑店剖面和武山剖面不同时代沉积物的 碎屑锆石 $\mathrm{U}-\mathrm{Pb}$ 年龄谱进行了分析和对比. 结果显示, 新生代以来, 该区物源至少经历了如下两次显著转变.

第一次转变发生在晚古近纪-早新近纪期间, 表现 为样品中 560 1100Ma的锆石颗粒所占比例的显著减 少以及200 360Ma锆石含量的增加. 如图3a和b所示, 560 1100Ma的锆石在古近纪样品YD-10中占 $69 \%$, 而 在随后的样品 $\mathrm{YDE}(32 \%$, 约 $30 \mathrm{Ma})$ 以及新近纪早期样 品(WS23与WS25)中显著减少甚至消失, 而与此同时, 200 360Ma的锆石颗粒发生了显著增加. 对于这一物 源转变, 认为其反映了古近纪晚期-新近纪早期西秦岭 向北的扩展隆升, 以及由此导致的物源区从西秦岭中 部或南部向北部迁移, 理由如下: (1) 古近纪的这套砾 岩大小混杂, 磨圆度差, 很显然是短距离搬运并快速 填充的洪积物(袁宝印等, 2007), 因而其很可能来源于 其南部距其较近的西秦岭. 低温热年代学的研究也表 明, 西秦岭在古近纪时期发生了快速剥露冷却(Clark 等, 2010), 因此这套洪积砾岩的形成很可能与这一过 程相关. (2) 这套砾岩中所含的560 1100Ma的锆石很 可能来自于秦岭地块, 因为祁连地块自身和周边的华
北克拉通基底岩石缺少 560 1100Ma的锆石颗粒(Darby 和Gehrels, 2006; Yang等, 2009; Gehrels等, 2011), 而从 扬子地块裂解出的南秦岭含有大量的 560 1100Ma的 锆石组分 (Ling等, 2010; Weislogel等, 2010). (3) 武山 剖面早中新世样品WS25(21.4Ma)和WS23(19.2Ma)中 包含大量200 360Ma锆石(谱峰为 $210 \mathrm{Ma}$ ), 与西秦岭北 部的岩体年龄(谱峰年龄219Ma)相一致(Cao等, 2011), 但其中 560 1100Ma的锆石含量极少, 这一方面意味 着之前包含大量560 1100Ma锆石的物源已不能再被 输送到武山地区, 另一方面也意味着包含 $210 \mathrm{Ma}$ 单一 锆石谱峰的新物源出现了. 秦岭北部的抬升可极好 解释这些现象, 如图 $4 \mathrm{a}$ 和 $\mathrm{b}$ 的模式所示: 一方面, 西秦 岭北部的抬升会导致分水岭向北迁移而阻挡来自秦 岭中部和/或南部的 560 1100Ma的锆石向北输送; 另 一方面, 西秦岭北部有较多200 250Ma的岩体( $\mathrm{CaO}$ 等, 2011; Liu等, 2015a), 这些岩体的隆升剥蚀无疑会形成 单一年龄谱峰的碎屑物. 其中, 西秦岭北部温泉岩体 因距武山地区较近, 其隆升剥蚀很可能为武山地区提 供 $210 \mathrm{Ma}$ 单一的锆石谱峰(图3-d2). 另外, 从西秦岭北 缘的现代河流样品来看(图3-d1), 其中 560 1100Ma锆 石所占比例与 $\mathrm{YDE}($ 约 $30 \mathrm{Ma}$ ) 样品相当, 并且普遍含有 较多200 360Ma的锆石颗粒, 指示着 YDE(约30Ma) 的 物源可能混入了较多西秦岭北缘的物质, 这意味着晚 古近纪西秦岭向北发生了扩展抬升.

第二次物源转变发生在19 11.5Ma期间, 表现为 200 360Ma的锆石含量的显著减少和360 560Ma锆石 含量的大量增加. 如图3所示, 200 360Ma的锆石含量 在早中新世样品WS25(21.4Ma) 和WS23(19.2Ma)中占 主导地位 $(>65 \%)$, 而380 460Ma的锆石颗粒在晚中新 世样品YD-9和YD-7中含量高达 $98 \%$. 对于这一物源 转变, 我们推测, 其很可能反映了中中新世晚期六盘 山南部的隆升剥蚀, 理由如下: (1) 从晚中新世样品 YD-9(11.5Ma)和YD-7(10.5Ma) 来看, 其380 460Ma的 锆石含量高达 $98 \%$, 指示其物源必定来自近源的岩体, 否则必将混入较多传输途中其他年龄段的锆石, 而且, 其物源不可能主要来自西秦岭北部, 否则, 其中必然同 时包含较多西秦岭北部200 250Ma岩体的锆石; (2) 六 盘山南部存在较多400 450Ma的岩体(Zhang等, 2006), 其年龄与YD-9 和YD-7的年龄主峰基本一致; (3) 已有 研究表明, 陇西地区在14 8Ma期间发生了显著的构造 活动, 这一构造事件不仅导致了六盘山的出现(宋友桂 
和方小敏, 2001; Zheng等, 2006; 梁美艳等, 2013), 也导 致了该区的风尘堆积发生了显著的侵蚀(Guo等, 2002; Hao和Guo, 2004; 袁宝印等, 2007; Ge等, 2012).

值得注意的是, 上述两次物源转变所揭示的构造 事件在时间上均与新生代青藏高原的阶段性隆升有较 好的一致性. 研究表明, 古近纪末-新近纪初青藏高原 北部发生了显著的构造活动(施雅风等, 1998; 王二七, 2013), 表现为拉鸡山(Lease等, 2012)、祁连山(George 等, 2001)、天山(Sobel等, 2006)、鄂拉山(Lu等, 2012) 等山体的快速隆升, 高原北部的阿尔金断裂快速左行 走滑(Jolivet等, 2001), 以及高原北部的盆地普遍缺失 该时期的沉积(张克信等, 2011; Xiao等, 2012a). 显然, 天水地区古近系与新近系之间的角度不整合很可能 也是高原此次构造活动的体现(袁宝印等, 2007). 而对 于19 11.5Ma期间的物源转变, 其很可能与 $14 \mathrm{Ma}$ 前后 青藏高原东北部的进一步扩展隆升相关, 这次隆升运 动导致了高原东北缘积石山的出现(Hough等, 2011), 兰州盆地和西宁盆地中新世湖相沉积的结束(岳乐平 等人, 2000; Xiao等, 2012a), 柴达木盆地东部的沉积速 率迅速增加(Fang等, 2007), 以及阿尔金山前出现巨厚 的磨拉石沉积(Sun等, 2005)等. 并且, 亚洲风尘平均物 质成分的变化很可能与该时期高原东北部的构造活 动产生的大量侵蚀物加入这一地区的荒漠系统有关 (Li等, 2011; Chen和 Li, 2013).

\section{2 区域地貌演化与风尘堆积的出现}

上述构造活动无疑会对天水-秦安地区新生代以 来的地貌演化产生深刻影响. 研究表明(Clark等, 2010; Duvall等, 2011), 新生代早期印度板块与欧亚板块碰 撞的远程效应可能已波及到该区, 可能导致了西秦岭 在古近纪时期的强烈隆升剥蚀, 并在西秦岭北麓堆积 了由厚层砾岩构成的冲洪积平原(袁宝印等, 2007). 本 文的碎屑锆石物源研究结果进一步揭示出这些洪积 砾岩中包含大量亲扬子地块的锆石颗粒(图3), 指示西 秦岭早期的隆升可能主要发生在其中部和/或南部地 区(图4a).

晚渐新世-早中新世是青藏高原扩展隆升的重要 时期(Jolivet等, 2001; Lease等, 2012; Pan等, 2013; 王二 七, 2013), 也是高原北部和东北部盆-山地貌形成的重 要时期(张克信等, 2011). 基于陇西地区古近纪与新近
纪地层之间的角度不整合接触关系, 袁宝印等(2007) 提出, 古近纪-新近纪之交研究区的地貌格局发生了重 大调整, 导致原有的洪积平原解体, 形成基岩台地和 沉陷盆地相间的地貌景观, 并在基岩台地和沉陷盆地 分别发育了风成和水成沉积序列; 同时, 这一事件也 导致了西秦岭向北扩展隆升, 使西和-礼县地区的古 近纪砾石层抬升,成为分隔山间盆地的分水岭. 本文 的碎屑锆石研究结果(图3)进一步支持了上述地貌演 化模式(图 $4 \mathrm{a}$ 和b): 武山剖面早中新世河流相沉积中包 含大量来自西秦岭北缘花岗岩体的200 250Ma的锆石 颗粒, 与来源于西秦岭中部和/或南部的古近纪洪积砾 岩的锆石年龄分布显著不同, 指示着西秦岭北部的隆 升; 并且, 秦安地区中新世风尘堆积的锆石年龄分布 也与武山剖面显著不同, 表明这两类发育于不同地貌 单元的沉积物源自不同的物源体系.

值得注意的是, 秦安地区开始出现风尘堆积的年 代与研究区晚渐新世-早中新世地貌格局的调整以及 青藏高原北部和东北部显著隆升的时代是一致的. 最 新的气候模拟研究发现, 高原北部的区域隆升可造成 亚洲内陆地区年降水量的显著减少、干旱区面积的 明显扩大和粉尘含量的显著增加(Liu等, 2015b). 同时, 模拟研究发现, 当高原高度达到现今一半时就可产生 明显的东亚季风环流, 且东亚冬季风对高原隆升的响 应比夏季风更敏感(Liu和Yin, 2002). 因此, 陇西地区 风尘堆积的出现很可能与 $25 \mathrm{Ma}$ 前后高原北部的强烈 隆升及其创造的物源区和风动力条件密切相关. 然而, 风尘堆积的发育除物源区和风动力条件外, 还需具备 相对平坦的地貌条件; 同时, 由于风尘堆积极易受到 侵蚀, 因此连续的风尘堆积的保存需要较为稳定的构 造条件(詹涛等, 2010; Ge等, 2012). 从这个意义上讲, 晚渐新世-早中新世青藏高原强烈的构造活动在秦安 地区所产生的基岩台地地貌, 为风尘堆积的出现提供 了理想的堆积场所. 对于此次构造活动, 我们推测, 其 规模和强度可能远超过之后的构造事件, 否则必将影 响基岩台地上长序列典型风尘堆积的完整保存.

有证据表明, 15 8Ma是青藏高原东北部隆升的 重要时期(安芷生等, 2006; Craddock等, 2011), 可能造 成了晚中新世时期六盘山的出现(宋友桂和方小敏, 2001; Zheng等, 2006)以及秦岭西南部地区的进一步隆 升(Enkelmann等, 2006). 从碎屑锆石证据来看(图3), 窑 店剖面早在11.5Ma就存在大量来自六盘山南部岩体 

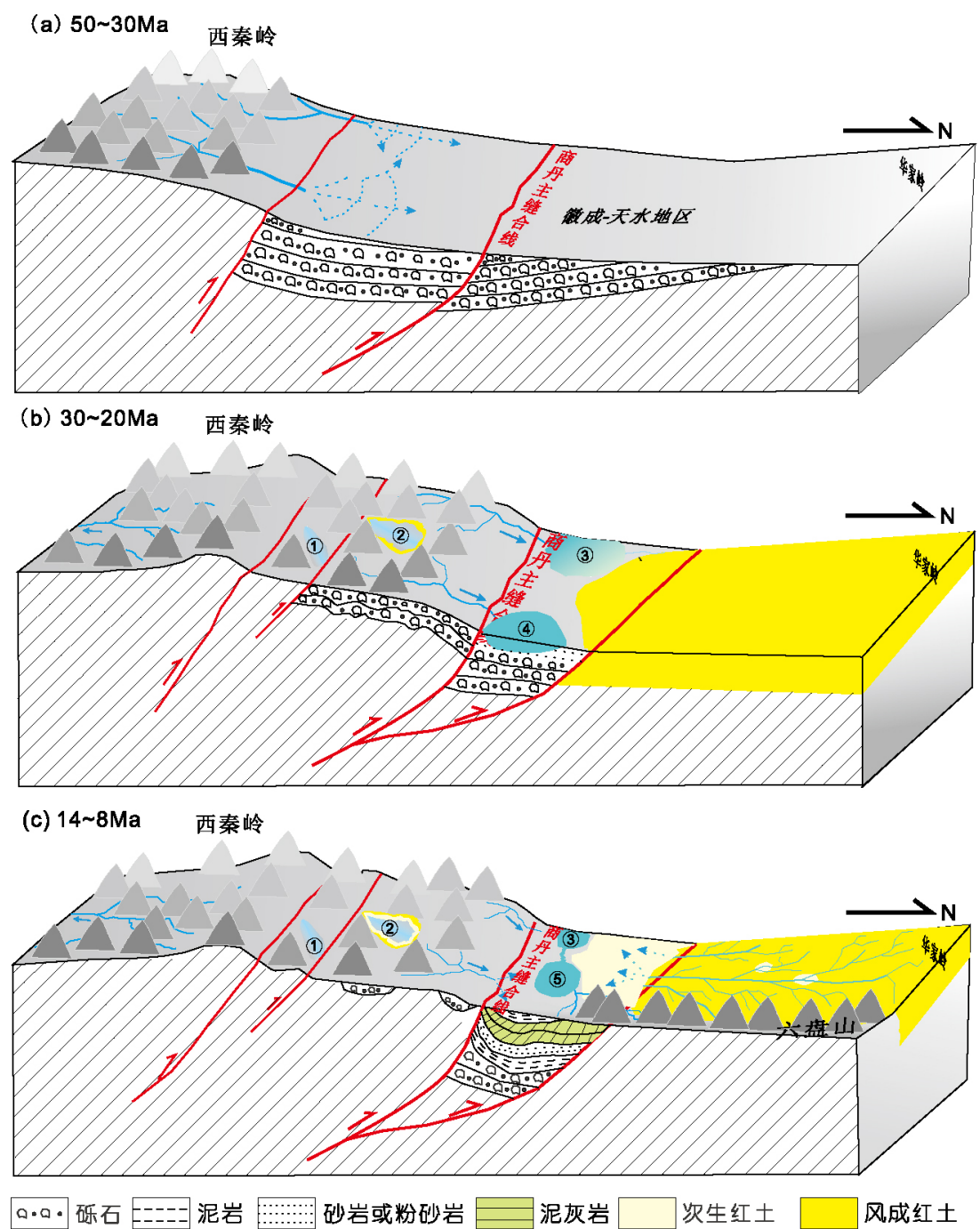

(1) 徽成盆地 (2) 西和-礼县盆地 (3) 武山盆地 (4) 天水地区 (5) 天水盆地

图 4 天水-秦安地区始新世至晚中新世地貌演化示意图

的物源, 指示着六盘山南部此时可能就已发生了较显 著的隆升剥蚀. 这一时间早于六盘山北部的隆升 $3 \mathrm{Ma}$ 以上(Zheng等, 2006), 指示着六盘山的隆升可能存在 空间不等时性(梁美艳等, 2013). 无疑, 六盘山的出现 会对天水地区的地貌产生重要影响(图4c): 一方面, 其 出现可能导致天水地区水系的重组, 这将为窑店剖面 中出现大量六盘山南部的物质提供搬运动力; 另一方 面, 六盘山的隆升也可能导致天水地区与其东部的渭 河盆地的分离, 并形成独立的天水盆地. 从窑店剖面 的沉积相来看, 天水盆地从约 $12.4 \mathrm{Ma}$ 开始形成并接受 河流相沉积, 从约 $9.2 \mathrm{Ma}$ 开始出现典型的湖相泥灰岩沉 积(李吉均等, 2007), 可能指示着研究区基岩台地与沉
陷盆地地貌的进一步分异. 与此同时, 秦安地区的风 尘堆积遭到一定程度的侵蚀, 并在一些侵蚀洼地中和 盆地中发育了河湖相沉积, 但在相对平坦的高地上一 直发育典型的风成红土-古土壤序列(Hao 和Guo, 2004; 袁宝印等, 2007). 无疑, 被侵蚀的风尘物质将在低洼地 区堆积. 值得注意的是, 窑店剖面的细颗粒湖相沉积 样品YD-2(约7.6Ma)的碎屑锆石年龄谱与中新世风尘 堆积、晚中新世-上新世三趾马红土、第四纪黄土极 为类似,而明显不同于窑店剖面和武山剖面的河流相 沉积(图3). 我们推测, 窑店剖面中的细颗粒湖相沉积 很可能主要是粉尘物质, 其可能源自典型风尘堆积的 侵蚀和/或落入湖盆中的亚洲内陆干旱区的粉尘物质. 


\section{6 结论}

本文通过对天水-秦安地区古近纪洪积砾岩、新 近纪河流和湖相沉积, 以及中新世风尘堆积的碎屑锆 石 $\mathrm{U}-\mathrm{Pb}$ 年龄物源分析, 探讨了该区新生代以来的构造 和地貌演化历史. 研究结果揭示出陇西地区从始新世 至晚中新世期间发生了两期显著的构造和地貌事件, 分别是: (1) 晚渐新世-早中新世期间的构造和地貌格 局调整, 其导致了研究区原有的洪积平原解体和西秦 岭向北的扩展隆升,并形成了基岩台地和沉陷盆地相 间的地貌景观, 为甘肃群风成和水成沉积序列的发育 提供了堆积场所; (2) 中中新世晚期六盘山南部的快 速隆升剥蚀, 其导致了天水盆地的形成, 奠定了该区 现代地貌格局的基础. 这两期事件在时间上均与新生 代青藏高原北部及东北部的阶段性隆升有较好的一 致性. 本文的研究揭示出秦安地区粉尘堆积的出现时 间以及被覆盖的基岩台地地貌的形成时间均与古近 纪末-新近纪初青藏高原北部的强烈隆升时间一致, 指 示着高原北部的隆升可能既为天水-秦安地区风尘堆 积的出现创造了物源和风动力条件, 同时也为其堆积 提供了有利的地貌条件. 而中中新世晚期六盘山的隆 起, 可能导致了该区盆一山地貌的进一步分异, 造成风 尘堆积一定程度的侵蚀, 并在盆地中发育了以粉尘物 质为主的典型湖相沉积.

致谢武建勋和周森同学参与了野外工作,肖国桥副 教授以及两位若名审稿人对本文提出了宝贵意见,特此 一并致谢. 对文中锆石 U-Pb年龄数据感兴趣的读者可通 过邮件向作者索取。

\section{参考文献}

安芷生, 张培震, 王二七, 王苏民, 强小科, 李力, 宋友桂, 常宏, 刘晓 东, 周卫健, 刘卫国, 曹军䩀, 李小强, 沈吉, 刘禹, 艾莉. 2006. 中 新世以来我国季风-干旱环境演化与青藏高原的生长. 第四纪研 究, 26: 678-693

地质部甘肃省地质局第三区域地质测量队. 1974. 秦安幅地质图 (1:20万)及说明书. 兰州: 五四三厂出版社

地质部陕西省地质局区域地质测量队. 1968. 天水幅地质图(1:20万) 及说明书. 武功: 测量队印刷厂

李吉均, 张军, 宋春晖, 赵志军, 张勇, 王修喜, 张建明, 崔巧玉. 2007. 陇中盆地灞河期地层的发现及意义. 中国科学 $\mathrm{D}$ 辑: 地球科学, 37: $52-60$
梁美艳, 王治祥, 周森, 宗克清, 胡兆初. 2013. 陇西地区甘肃群 的物质来源及其构造和古气候指示. 中国科学: 地球科学, 12 : 2007-2015

强小科, 安芷生, 宋友桂, 常宏, 孙有斌, 刘卫国, 敖红, 董吉宝, 符超 峰, 吴枫, 卢风艳, 蔡演军, 周卫健, 曹军骥, 徐新文, 艾莉. 2010. 晚渐新世以来中国黄土高原风成红粘土序列的发现: 亚洲内陆 干旱化起源的新记录. 中国科学: 地球科学, 40: 1479-1488

翟毓沛, 蔡体梁. 1984. 甘肃的第三系. 甘肃地质, 2: 1-40

施雅风, 汤禁苍, 马玉贞. 1998. 青藏高原二期隆升与亚洲季风孕育 关系探讨. 中国科学 D辑: 地球科学, 28: 263-271

宋友桂, 方小敏. 2001. 晚新生代六盘山隆升过程初探. 中国科学 D 辑: 地球科学, 31: 142-148

王二七. 2013. 青藏高原大地构造演化一一主要构造一热事件的制 约及其成因探讨. 地质科学, 48: 334-353

王志才, 张培震, 张广良, 李传友, 郑德文, 袁道阳. 2006. 西秦岭北 缘构造带的新生代构造活动——兼论对青藏高原东北缘形成过 程的指示意义. 地学前缘, 13: 119-135

肖国桥, 张春霞, 郭正堂. 2014. 晚渐新世-早中新世青藏高原隆升 与东亚季风演化. 自然杂志, 6: 165-169

袁宝印, 郭正堂, 郝青振, 彭淑贞, 乔彦松, 吴海斌, 肖国桥, 葛俊逸, 孙斌, 周金金, 尹秋珍, 梁美艳, 秦利, 刘恋, 姚政权, 刘东生. 2007 . 天水-秦安一带中新世黄土堆积区沉积-地貌演化. 第四纪研究, 27: $161-171$

岳乐平, Heller F, 邱占祥, 张莉, 颉光普, 邱铸鼎, 张云翔. 2000. 兰州盆 地第三系磁性地层年代与古环境记录. 科学通报, 45: 1998-2003

詹涛, 郭正堂, 吴海斌, 葛俊逸, 周金金, 武春林, 曾方明. 2010. 华家岭 山地中新世风成红土堆积与西部黄土高原地貌演化. 中国科学: 地球科学, 40: 1040-1047

张克信, 王国灿, 季军良, 骆满生, 寇晓虎, 王岳明, 徐亚东, 陈奋宁, 陈锐明, 宋博文, 张楗钰, 梁银平. 2011. 青藏高原古近纪-新近纪 地层分区与序列及其对隆升的响应. 中国科学: 地球科学, 12 : $1632-1654$

Andersen T. 2002. Correction of common lead in U-Pb analyses that do not report ${ }^{204} \mathrm{~Pb}$. Chem Geol, 192: 59-79

An Z S, Kutzbach J E, Prell W L, Porter S C. 2001. Evolution of Asian monsoons and phased uplift of the Himalaya-Tibetan Plateau since Late Miocene times.. Nature, 411: 62-66

Cao X, Lü X, Yao S, Mei W, Zou X, Chen C, Liu S, Zhang P, Su Y, Zhang B. 2011. LA-ICP-MS U-Pb zircon geochronology, geochemistry and kinetics of the Wenquan ore-bearing granites from West Qinling, China. Ore Geol Rev, 43: 120-131

Che X, Li G. 2013. Binary sources of loess on the Chinese Loess Plateau revealed by U-Pb ages of zircon. Quat Res, 80: 545-551

Chen Z, Li G. 2013. Evolving sources of eolian detritus on the Chinese Loess Plateau since early Miocene: Tectonic and climatic controls. Earth Planet Sci Lett, 371-372: 220-225 
Clark M K, Farley K A, Zheng D, Wang Z, Duvall A R. 2010. Early Cenozoic faulting of the northern Tibetan Plateau margin from apatite (U-Th)/He ages. Earth Planet Sci Lett, 296: 78-88

Craddock W, Kirby E, Zhang H. 2011. Late Miocene-Pliocene range growth in the interior of the northeastern Tibetan Plateau. Lithosphere, 3: 420-438

Darby B J, Gehrels G. 2006. Detrital zircon reference for the North China block. J Asian Earth Sci, 26: 637-648

Duvall A R, Clark M K, van der Pluijm B A, Li C. 2011. Direct dating of Eocene reverse faulting in northeastern Tibet using Ar-dating of fault clays and low-temperature thermochronometry. Earth Planet Sci Lett, 304: $520-526$

Enkelmann E, Ratschbacher L, Jonckheere R, Nestler R, Fleischer M, Gloaguen R, Hacker B R, Zhang Y Q, Ma Y S. 2006. Cenozoic exhumation and deformation of northeastern Tibet and the Qinling: Is Tibetan lower crustal flow diverging around the Sichuan Basin? Geol Soc Am Bull, 118: 651-671

Fang X, Zhang W, Meng Q, Gao J, Wang X, King J, Song C, Dai S, Miao Y. 2007. High-resolution magnetostratigraphy of the Neogene Huaitoutala section in the eastern Qaidam Basin on the NE Tibetan Plateau, Qinghai Province, China and its implication on tectonic uplift of the NE Tibetan Plateau. Earth Planet Sci Lett, 258: 293-306

Ge J, Guo Z, Zhan T, Yao Z, Deng C, Oldfield F. 2012. Magnetostratigraphy of the Xihe loess-soil sequence and implication for late Neogene deformation of the West Qinling Mountains. Geophys J Int, 189: 1399-1408

Gehrels G, Kapp P, Decelles P, Pullen A, Blakey R, Weislogel A, Ding L, Guynn J, Martin A, McQuarrie N, Yin A. 2011. Detrital zircon geochronology of pre-Tertiary strata in the Tibetan-Himalayan orogen. Tectonics, 30: TC5016

George A D, Marshallsea S J, Wyrwoll K H, Jie C, Yanchou L. 2001. Miocene cooling in the northern Qilian Shan, northeastern margin of the Tibetan Plateau, revealed by apatite fission-track and vitrinite-reflectance analysis. Geology, 29: 939-942

Guo Z T, Ruddiman W F, Hao Q Z, Wu H B, Qiao Y S, Zhu R X, Peng S Z, Wei J J, Yuan B Y, Liu T S. 2002. Onset of Asian desertification by 22 Myr ago inferred from loess deposits in China. Nature, 416: 159-163

Guo Z T, Sun B, Zhang Z S, Peng S Z, Xiao G Q, Ge J Y, Hao Q Z, Qiao Y S, Liang M Y, Liu J F, Yin Q Z, Wei J J. 2008. A major reorganization of Asian climate by the early Miocene. Clim Past, 4: $153-174$

Guo Z T, Ge J Y, Xiao G Q, Hao Q Z, Wu H B, Zhan T, Liu L, Qin L, Zeng F M, Yuan B Y. 2010. Comment on "Mudflat/distal fan and shallow lake sedimentation (upper Vallesian-Turolian) in the Tianshui Basin, Central China: Evidence against the late Miocene eolian loess” by A.M. Alonso-Zarza, Z. Zhao, C.H. Song, J.J. Li, J. Zhang, A. Martín-Pérez, R. Martín-García, X.X. Wang, Y. Zhang and M.H. Zhang [Sedimentary Geology 222 (2009) 42-51]. Sediment Geol, 230: $86-89$

Hao Q, Guo Z. 2004. Magnetostratigraphy of a late Miocene-Pliocene loess-soil sequence in the western Loess Plateau in China. Geophys Res Lett, 31: L09209

Hao Q, Guo Z. 2007. Magnetostratigraphy of an early-middle Miocene loess-soil sequence in the western Loess Plateau of China. Geophys Res Lett, 34: L18305

Hough B G, Garzione C N, Wang Z, Lease R O, Burbank D W, Yuan D. 2011. Stable isotope evidence for topographic growth and basin segmentation: Implications for the evolution of the NE Tibetan Plateau. Geol Soc Am Bull, 123: 168-185

Jolivet M, Brunel M, Seward D, Xu Z, Yang J, Roger F, Tapponnier P, Malavieille J, Arnaud N, Wu C. 2001. Mesozoic and Cenozoic tectonics of the northern edge of the Tibetan Plateau: Fission-track constraints. Tectonophysics, 343: 111-134

Lease R O, Burbank D W, Hough B, Wang Z, Yuan D. 2012. Pulsed Miocene range growth in northeastern Tibet: Insights from Xunhua Basin magnetostratigraphy and provenance. Geol Soc Am Bull, 124: 657-677

Li G, Pettke T, Chen J. 2011. Increasing Nd isotopic ratio of Asian dust indicates progressive uplift of the north Tibetan Plateau since the middle Miocene. Geology, 39: 199-202

Li Y, Wang C, Dai J, Xu G, Hou Y, Li X. 2015. Propagation of the deformation and growth of the Tibetan-Himalayan orogen: A review. Earth-Sci Rev, 143: 36-61

Ling W L, Duan R C, Liu X M, Cheng J P, Mao X W, Peng L H, Liu Z X, Yang H M, Ren B F. 2010. U-Pb dating of detrital zircons from the Wudangshan Group in the South Qinling and its geological significance. Chin Sci Bull, 55: 2440-2448

Liu S, Li J, Stockli D F, Song C, Nie J, Peng T, Wang X, He K, Hui Z, Zhang J. 2015a. Late Tertiary reorganizations of deformation in northeastern Tibet constrained by stratigraphy and provenance data from eastern Longzhong Basin. J Geophys Res-Solid Earth, 120: $5804-5821$

Liu X D, Dong B W. 2013. Influence of the Tibetan Plateau uplift on the Asian monsoon-arid environment evolution. Chin Sci Bull, 58: 4277-4291

Liu X, Yin Z Y. 2002. Sensitivity of East Asian monsoon climate to the uplift of the Tibetan Plateau. Paleogeogr Paleoclimatol Paleoecol, 183: $223-245$

Liu X, Sun H, Miao Y, Dong B, Yin Z Y. 2015b. Impacts of uplift of northern Tibetan Plateau and formation of Asian inland deserts on regional climate and environment. Quat Sci Rev, 116: 1-14 
Liu Y, Gao S, Hu Z, Gao C, Zong K, Wang D. 2010. Continental and oceanic crust recycling-induced melt-peridotite interactions in the Trans-North China Orogen: U-Pb dating, Hf isotopes and trace elements in zircons from mantle xenoliths. J Petrol, 51: 537-571

Lu H, Wang E, Shi X, Meng K. 2012. Cenozoic tectonic evolution of the Elashan range and its surroundings, northern Tibetan Plateau as constrained by paleomagnetism and apatite fission track analyses. Tectonophysics, 580: 150-161

Meng Q R, Zhang G W. 2000. Geologic framework and tectonic evolution of the Qinling orogen, central China. Tectonophysics, 323: 183-196

Nie J, Peng W, Möller A, Song Y, Stockli D F, Stevens T, Horton B K, Liu S, Bird A, Oalmann J, Gong H, Fang X. 2014. Provenance of the upper Miocene-Pliocene Red Clay deposits of the Chinese Loess Plateau. Earth Planet Sci Lett, 407: 35-47

Pan B T, Li Q Y, Hu X F, Geng H P, Liu Z B, Jiang S F, Yuan W M. 2013. Cretaceous and Cenozoic cooling history of the eastern Qilian Shan, north-eastern margin of the Tibetan Plateau: Evidence from apatite fission-track analysis. Terra Nova, 25: 431-438

Pullen A, Kapp P, McCallister A T, Chang H, Gehrels G E, Garzione C N, Heermance R V, Ding L. 2011. Qaidam Basin and northern Tibetan Plateau as dust sources for the Chinese Loess Plateau and paleoclimatic implications. Geology, 39: 1031-1034

Ramstein G, Fluteau F, Besse J, Joussaume S. 1997. Effect of orogeny, plate motion and land-sea distribution on Eurasian climate change over the past 30 million years. Nature, 386: 788-795

Shang Y, Beets C J, Tang H, Prins M A, Lahaye Y, van Elsas R, Sukselainen L, Kaakinen A. 2016. Variations in the provenance of the late Neogene Red Clay deposits in northern China. Earth Planet Sci Lett, 439: 88-100

Sobel E R, Chen J, Heermance R V. 2006. Late Oligocene-Early Miocene initiation of shortening in the Southwestern Chinese Tian Shan: Implications for Neogene shortening rate variations. Earth Planet Sci Lett, 247: 70-81

Stevens T, Palk C, Carter A, Lu H, Clift P D. 2010. Assessing the provenance of loess and desert sediments in northern China using $\mathrm{U}-\mathrm{Pb}$ dating and morphology of detrital zircons. Geol Soc Am Bull, 122: 1331-1344

Sun J, Zhu R, An Z. 2005. Tectonic uplift in the northern Tibetan Plateau since 13.7 Ma ago inferred from molasse deposits along the Altyn Tagh Fault. Earth Planet Sci Lett, 235: 641-653

Sun X, Wang P. 2005. How old is the Asian monsoon system?-Palaeobotanical records from China. Paleogeogr Paleoclimatol Paleoecol, 222: $181-222$

Vermeesch P. 2012. On the visualisation of detrital age distributions.
Chem Geol, 312-313: 190-194

Wang C, Dai J, Zhao X, Li Y, Graham S A, He D, Ran B, Meng J. 2014. Outward-growth of the Tibetan Plateau during the Cenozoic: A review. Tectonophysics, 621: 1-43

Wang X, Zattin M, Li J, Song C, Peng T, Liu S, Liu B. 2011. Eocene to Pliocene exhumation history of the Tianshui-Huicheng region determined by Apatite fission track thermochronology: Implications for evolution of the northeastern Tibetan Plateau margin. J Asian Earth Sci, 42: 97-110

Wang Z, Zhang P, Garzione C N, Lease R O, Zhang G, Zheng D, Hough B, Yuan D, Li C, Liu J, Wu Q. 2012. Magnetostratigraphy and depositional history of the Miocene Wushan basin on the NE Tibetan plateau, China: Implications for middle Miocene tectonics of the West Qinling fault zone. J Asian Earth Sci, 44: 189-202

Weislogel A L, Graham S A, Chang E Z, Wooden J L, Gehrels G E. 2010. Detrital zircon provenance from three turbidite depocenters of the Middle-Upper Triassic Songpan-Ganzi complex, central China: Record of collisional tectonics, erosional exhumation, and sediment production. Geol Soc Am Bull, 122: 2041-2062

Xiao G, Guo Z, Dupont-Nivet G, Lu H, Wu N, Ge J, Hao Q, Peng S, Li F, Abels H A, Zhang K. 2012a. Evidence for northeastern Tibetan Plateau uplift between 25 and $20 \mathrm{Ma}$ in the sedimentary archive of the Xining Basin, Northwestern China. Earth Planet Sci Lett, 317-318: 185-195

Xiao G, Zong K, Li G, Hu Z, Dupont-Nivet G, Peng S, Zhang K. 2012b. Spatial and glacial-interglacial variations in provenance of the Chinese Loess Plateau. Geophys Res Lett, 39: L20715

Xu Y J, Du Y S, Cawood P A, Guo H, Huang H, An Z H. 2010. Detrital zircon record of continental collision: Assembly of the Qilian Orogen, China. Sediment Geol, 230: 35-45

Yang J, Gao S, Chen C, Tang Y, Yuan H, Gong H, Xie S, Wang J. 2009. Episodic crustal growth of North China as revealed by $\mathrm{U}-\mathrm{Pb}$ age and Hf isotopes of detrital zircons from modern rivers. Geochim Cosmochim Acta, 73: 2660-2673

Zhang H F, Zhang B R, Harris N, Zhang L, Chen Y L, Chen N S, Zhao $\mathrm{Z}$ D. 2006. U-Pb zircon SHRIMP ages, geochemical and Sr-Nd-Pb isotopic compositions of intrusive rocks from the Longshan-Tianshui area in the southeast corner of the Qilian orogenic belt, China: Constraints on petrogenesis and tectonic affinity. J Asian Earth Sci, 27: $751-764$

Zheng D, Zhang P Z, Wan J, Yuan D, Li C, Yin G, Zhang G, Wang Z, Min W, Chen J. 2006. Rapid exhumation at $\sim 8$ Ma on the Liupan Shan thrust fault from apatite fission-track thermochronology: Implications for growth of the northeastern Tibetan Plateau margin. Earth Planet Sci Lett, 248: 198-208 